\title{
O Grupo de Estudos Afro-brasileiros e Indígenas - GEABI e a formação de professores no estado do Pará
}

\author{
Léia Gonçalves de Freitas ${ }^{1}$ \\ Vilma Aparecida de Pinho²
}

\begin{abstract}
RESUMO
Este trabalho objetiva apresentar e analisar as contribuições do Grupo de estudos afro-brasileiros e indígenas - GEABI, para a formação de professores em Relações Étnico-raciais na Transxingu (Altamira) e Baixo Tocantins (Cametá) - PA, a partir da Lei $n^{\circ} 10.639 / 2003$, buscando identificar as abordagens teóricas e metodológicas adotadas, bem como as repercussões dessa formação nas práticas pedagógicas dos professores. A metodologia utilizada foi a pesquisa documental com abordagem qualitativa. As fontes consultadas foram os Projetos Pedagógicos do curso de Pedagogia, do curso de Especialização em Educação Diversidade e Sociedade e do curso de Mestrado em Educação e Cultura - PPGEDUC; o projeto PROINT/GEABI; folder dos eventos realizados, Plano de trabalho e Relatório das formações. Os resultados apontam que o GEABI, ao longo dos anos, foi impulsionador de mudanças pedagógicas para a inclusão de alunos/as negros/as na escola, ao possibilitar a formação de professores para o trato das questões em Relações Étnico-raciais. Neste sentido, afirmamos que os efeitos dessas ações impactaram sobremaneira as políticas de formação inicial e continuada de professores, contribuindo para mudanças do cenário Transxingu (Altamira) e Baixo Tocantins (Cametá), que tem sido marcado por conflitos, no que se refere à formação docente. Conflitos esses divididos em dois movimentos: (a) um que atribui ao espaço formativo a função de preparar futuros professores nas competências entendidas como centrais em um mundo globalizado; (b) e outro que compreende tal espaço como campo discursivo com potenciais de atuação na construção de identidades docentes críticas, comprometidas com a valorização da pluralidade cultural.
\end{abstract}

Palavras-chave: GEABI. Étnico-raciais. Formação de professores.

\section{The Group of Afro-brazilian and Indigenous Studies - GEABI and the teacher education in the state of Pará}

\begin{abstract}
This study aims to present and analyze the contributions of the Afro-Brazilian and Indigenous Studies Group (GEABI) for the teacher education in Ethnic-racial Relations

\footnotetext{
1 Doutora em Educação/UFPA. Universidade Federal do Pará - Altamira/PA. ORCID ID:
} https://orcid.org/0000-0003-1852-1106 E-mail: leiafreitas@ufpa.br

2 Doutora em Educação. Universidade Federal do Pará - Altamira/PA ORCID ID: https://orcid.org/0000-0002-2544-0841 E-mail: vilmaaparecidadepinho@gmail.com
\end{abstract}


in Transxingu (Altamira) and in Tocantins (Cametá) - PA, under Law No. 10,639 / 2003, seeking to identify the theoretical and methodological approaches adopted, as well as the repercussions of this training on teachers' pedagogical practice. The methodology used was documentary research with a qualitative approach. The sources consulted were the Pedagogical Project of the Pedagogy course, the Specialization course in Diversity and Society Education and the Master's Course in Education and Culture - PPGEDUC; the PROINT / GEABI project; folder of the events carried out, work plan and training report. Regarding the results, we conclude that GEABI, over the years, has been the driving force for pedagogical changes to the inclusion of black students in school, by educating teachers to deal with ethnicracial relations issues. In this sense, we affirm that the effects of these actions impacted, in large part, the initial and continuing teacher education policies, contributing to changes in the Transxingu (Altamira) and lower Tocantins (Cametá) scenario, which has been marked by conflicts in relation to teacher education. These conflicts are divided into two movements: (a) that attributes to the formative space the function of education future teachers in the competences understood as central in a globalized world; (b) and those who understand such space as a discursive field with potential of acting in the construction of critical teaching identities, committed to the valorization of cultural plurality.

Keywords: GEABI. Ethnic-racial. Teacher training.

\section{Grupo de Estudios Afro-brasileños y Indígenas - GEABI y la formación de professores en el estado de PARÁ}

\section{Resumen}

El objetivo de este trabajo es presentar y analizar las contribuciones del Grupo de Estudio Indígena, Brasileño y Africano - GEABI, para la formación de docentes en relaciones étnico-raciales en Transxingu (Altamira) y Tocantins inferiores (Cametá) AP, de la Ley $N \circ$ 10.639. / 2003. Se busca analizar los enfoques teóricos y metodológicos adoptados, así como las repercusiones de esta formación en la práctica pedagógica de los docentes. La metodología utilizada fue la investigación documental con enfoque cualitativo. Las fuentes consultadas fueron el Proyecto Pedagógico del curso de Pedagogía, el Curso de Especialización en Educación en Diversidad y Sociedad y el Curso de Maestría en Educación y Cultura - PPGEDUC; el proyecto PROINT / GEABl; carpeta de eventos, plan de trabajo e informe de capacitación. Se concluye que, a lo largo de los años, el GEABI ha sido un motor para impulsar cambios pedagógicos para la inclusión de estudiantes negros en la escuela y logró capacitar a los maestros para tratar temas sobre relaciones étnicas y raciales. En este sentido, afirmamos que los efectos de estas acciones han tenido un gran impacto en las políticas de formación docente inicial y continua, contribuyendo a los cambios en el escenario Transxingu (Altamira) y Tocantins (Cametá), que se caracterizan por conflictos, en los que se refiere a la formación del profesorado. Estos conflictos se dividen en dos movimientos: por un lado, el referido al espacio formativo, es decir, la función de preparar a los futuros docentes en las competencias entendidas como centrales en un mundo globalizado; y, por otra parte, aquellos que entienden este espacio como un campo discursivo con potencial para la construcción de identidades críticas de enseñanza y comprometidos con la pluralidad cultural.

Palabras clave: GEABI, étnico-racial. Formación de profesores. 


\section{Introdução}

Este trabalho objetiva apresentar e analisar as contribuições do Grupo de estudos afro-brasileiros e indígenas - GEABI, para formação de professores em Relações Étnico-raciais na Transxingu (Altamira) e baixo Tocantins (Cametá) - PA, a partir da Lei $n^{\circ} 10.639 / 2003$, buscando identificar as abordagens teóricas e metodológicas adotadas, bem como as repercussões dessa formação na prática pedagógica dos professores. Neste sentido, procuramos discutir as formações ofertadas na Transxingu (Altamira) e baixo Tocantins (Cametá)- PA pelo GEABI, seus objetivos, abordagens teóricas e metodológicas e quais os efeitos dessa formação na prática pedagógica dos professores.

A metodologia utilizada foi o levantamento documental, com abordagem qualitativa, na perspectiva defendida por Lüdke e André (2012, p. 39), quando afirmam que uma das vantagens da pesquisa documental é que "os documentos podem ser consultados várias vezes e inclusive servir de base a diferentes estudos, o que dá mais estabilidade aos resultados obtidos". Em relação às fontes consultadas, analisamos os seguintes documentos: Projetos Pedagógicos do curso de Pedagogia, do curso de Especialização em Educação, Diversidade e Sociedade - GEABI/UFPA e do curso de Mestrado em Educação e Cultura - PPGEDUC; projeto PROINT/GEABI, folder dos eventos, Plano de trabalho do grupo e Relatório das formações. O recorte temporal compreende os anos de 2010 a 2019.

Cabe ressaltar que, antes desse levantamento, foi efetivada uma pesquisa bibliográfica para compreendermos a base conceitual dos documentos normativos, que são: (a) a Lei no 10.639/2003; (b) as DCNERER (2004); (c) e, o PNI das DCNERER (2009). Esta pesquisa possibilitou o confronto teórico-prático das Ações Afirmativas da formação de professores realizada, ao mesmo tempo em que foi determinante para o conhecimento teórico do problema por nós pesquisado. 


\section{Contribuições sociopolíticas do Grupo de estudos afro-brasileiros e indígenas - GEABI para a formação de professores em Relações Étnico-raciais}

O GEABI é um grupo de pesquisa, ensino e extensão ${ }^{3}$ da Universidade Federal do Pará, registrado no diretório de pesquisa do CNPq, com um perfil multidisciplinar (Pedagogia, Antropologia, Direito, Sociologia, Economia, Arqueologia, Biologia, Letras). Foi criado em 2010, com o objetivo de pesquisar as dinâmicas culturais, o cotidiano e a história dos Afro-Brasileiros e Indígenas na região amazônica paraense; a educação e formação, como processos de reconhecimento e o acesso aos bens culturais das sociedades que compõem a diversidade brasileira; questões sobre a educação da população negra e educação indígena e currículo; e políticas públicas de formação docente para a diversidade étnico-racial (GEABI, 2010). O grupo conta atualmente com cinco integrantes entre professores e alunos de graduação.

Dentre os projetos do GEABI desenvolvidos na área da formação continuada de professores, em Educação para as Relações Étnico-Raciais, estão, em 2010 e 2011: Projeto integrado "Interdisciplinaridade, ensino, pesquisa e extensão em práticas pedagógicas inovadoras no laboratório de pedagogia", com o propósito de "fomentar a criação de experiências inovadoras na formação inicial em Pedagogia juntando esforços para o cumprimento das Leis $n^{\circ}$ 10.639/2003 e $n^{\circ} 11.645 / 2008$ para a superação de práticas de racismo e de discriminação" (PROJETO INTEGRADO PROINT GEABI, 2010, p. 06).

\footnotetext{
3 "O conceito de indissociabilidade entre ensino, pesquisa e extensão, como referência para a organização do trabalho pedagógico, embora de difícil concretização em face das condições políticas e estruturais da educação superior, tornou-se premissa para pensar e propor alternativas para esse nível de ensino, incorporando-se à história da universidade brasileira como contraponto aos modelos baseados na lógica do mercado. A expressão 'indissociabilidade entre ensino, pesquisa e extensão' consagrada pela Constituição de 1988, não deve ser considerada como uma fraseologia de efeito, mas como uma síntese atual da história educacional brasileira que aponta diretamente para a construção de uma universidade de um bom nível acadêmico, pública, autônoma, democrática, que se coloca a serviço da realização de uma sociedade independente e soberana científica, tecnológica e culturalmente, voltada para os interesses concretos da população brasileira (MAZZILLI, 2011 , p. 215)".
} 
O GEABI ofertou oito cursos de curta duração - com carga horária de 20 horas cada um, durante os anos 2010/2011, com os seguintes temas: (a) Arte e Educação; (b) Brinquedoteca; (c) Literatura infanto-juvenil e diversidade em relações étnico-raciais; (d) Mostra de filme: Cinema e Infância; (e) Inclusão digital para pessoas com deficiências e Tecnologia Assistiva (TA); (f) Expressão musical e linguagem; (g) Cultura corporal; (h) e, Educação em direitos humanos, legislação da educação e diversidade cultural. Frequentaram esses os cursos 250 professores de Educação Infantil da rede municipal de ensino e os seis bolsistas do projeto.

Dentre os oito cursos oferecidos, destacamos: (a) Literatura infantojuvenil e livro didático: uma análise do racismo no plano simbólico, cujo objetivo foi realizar uma análise do racismo no plano simbólico a partir de discussões de conceitos e origens do racismo, branqueamento, poder simbólico, ideologia e construção de identidade; (b) Cultura corporal e arte, com intuito de pensar a prática pedagógica a partir do movimento como instrumento lúdico no processo de alfabetização, buscando a valorização da criança branca, negra e indígena; e (c) Formação de professores brinquedistas no Hospital Regional da Transamazônica: educação e diversidade cultural, com o objetivo de orientar a formação docente quanto ao acompanhamento e planejamento das atividades em ambiente hospitalar numa perspectiva multicultural.

Em novembro de 2012, aconteceu o Seminário "História e cultura afrobrasileira e indígena: políticas educacionais, currículo e identidade", cuja programação contou com cinco palestras, oficinas, apresentações culturais e rodas de conversas. Os temas das palestras foram: (a) Políticas educacionais para a população negra e indígena; (b) Religião de matriz africana: cultura e identidade no contexto escolar; (c) Direitos humanos e indígenas: perspectivas para construção da doutrina da proteção plural; (d) Os desafios atuais da educação brasileira: das relações étnico-raciais a educação do campo; e (e) Populações negras e indígenas: diretrizes nacionais de educação. 
O seminário teve o intuito de promover o debate sobre as políticas de ações afirmativas para a inserção de jovens negros e indígenas no ensino superior, em face das conquistas na UFPA. O público alvo foram professores e estudantes de educação básica, da graduação e pós-graduação do município de Altamira - PA e demais municípios da região Transamazônica e Xingu. No evento também houve lançamento do livro "Relações étnicoraciais, educação e produção do conhecimento: 10 anos do GT-21 ANPEd" organizado pelas professoras doutoras Nilma Lino Gomes, Silvani dos Santos Valentim e Vilma Aparecida de Pinho.

Em 2013, foi ofertado curso de Especialização em "Educação, Diversidade e Sociedade", na modalidade regular/presencial, com os seguintes objetivos: "viabilizar a formação para a implementação das diretrizes curriculares nacionais que se referem aos conhecimentos sobre a cultura e história afro-brasileiras e indígenas em todos os níveis de ensino" (GEABI, 2013, p. 03).

O curso foi aberto à comunidade local, mas previa "a prática de política de ação afirmativa para os autodeclarados negros, indígenas e para professores das redes municipais e estaduais de educação básica; e integrantes de Movimento Social" (GEABI, 2013, p. 04). Sua organização curricular se distribuiu em três eixos: o primeiro é intitulado "Educação e diversidade", composto por disciplinas com carga horária de 30 horas, sendo 25 horas teóricas e 05 práticas (Técnicas e abordagens teóricas e metodológicas de pesquisa I; Direitos humanos, diversidade cultural e educação; Diversidade, desigualdade e educação da população negra; e Ełnografia da comunicação).

O segundo eixo, inititulado "Memória, patrimônio e identidade", abrangeu as seguintes disciplinas: (a) Técnicas e abordagens teóricas e metodológicas de pesquisa II, com carga horária de 35 horas teóricas e cinco práticas; (b) Patrimônios e diversidade; (c) Educação, cultura e sociobiodiversidade; e (d) Identidade étnica e diversidade cultural. Com exceção da primeira disciplina deste eixo, todas têm carga horária de 25 horas teóricas e 05 práticas. 
O terceiro eixo, denominado de "Políticas públicas, direitos territoriais e meio ambiente", foi composto das seguintes disciplinas: (a) Condições socioeconômicas das populações brasileiras: diferença e desigualdade em questão; (b) Terra, território e populações no Brasil; (c) Movimentos sociais, diversidade e educação, todas com 30 horas, sendo 25 horas teóricas e 05 práticas; (d) Técnicas e abordagens teóricas e metodológicas de pesquisa III, com 35 horas teóricas e 05 práticas. A disciplina final foi orientação para o Trabalho de Conclusão de Curso, com 60 horas. Todas as disciplinas totalizam 470 horas (395 teóricas e 75 práticas).

Com relação às competências e habilitações, o Projeto Pedagógico deste curso destaca: (a) compreensão ampla e consistente dos aportes teórico-conceituais que fundamentam as discussões no campo da educação, diversidade e sociedade; (b) capacidade de estabelecer diálogos interdisciplinares entre diferentes áreas de conhecimento (Sociologia, Antropologia, Pedagogia, Letras, Direito, Agronomia e Biologia) em suas confluências com os campos da educação e da diversidade, de modo a enriquecer a compreensão crítica dos fenômenos sociais e educativos; (c) compreensão dos processos de constituição das identidades e diferenças culturais na Amazônia, como possibilidade de elaborar e propor políticas públicas e educacionais que levem em consideração as especificidades socioculturais da região (GEABI, 2013).

Em 2014, aconteceram formações com professores da rede municipal de ensino na Escola Municipal de Ensino Fundamental Anísio Uchoa. O objetivo do curso "História e Cultura Afro-brasileira" foi discutir, analisar e implementar a Lei $n^{\circ} 10.639 / 2003$ no cotidiano escolar. O total de participantes foi aproximadamente de 16 professores. Os encontros eram realizados em âmbito escolar, evitando que os professores se deslocassem do seu local de trabalho. O curso, com duração de 40 horas, teve início no mês de maio e término em dezembro de 2014. Ao final os participantes receberam certificados.

Ainda em 2014, foram desenvolvidas pesquisas por meio do projeto "Fatores de proteção e risco no contexto da grande obra da Usina 
Hidrelétrica (UHE) de Belo Monte: análise dos impactos socioambientais e culturais na formação de criança e adolescente de famílias remanejadas", com o intuito de analisar, sobretudo, os fatores de proteção e risco da criança e do adolescente impactados pela construção da UHE de Belo Monte, uma vez que as famílias foram atingidas, dependendo da região, pelo represamento ou pela seca, que modificaram seus modos de vida e impactaram o acesso às instituições de garantia de direitos, principalmente a escola. Tais pesquisas tiveram como objeto as condições potencializadoras e/ou fragilizadoras do desenvolvimento humano (GEABI, 2014).

No ano de 2015, o curso "História e Cultura Afro-brasileira" aconteceu na Escola Municipal Doutor Octacílio Lino, visando a implantação da Lei ${ }^{\circ}$ 10.639/2003, na perspectiva de verificar seus efeitos na prática pedagógica dos professores. Participaram do curso 20 professores. Além de discussões teóricas, foram promovidas oficinas da boneca abayomi, que tem origem iorubá e costuma ser uma boneca negra, significando aquele que traz felicidade ou alegria. No curso ainda foram trabalhados literatura infantojuvenil e estereótipos e livros didáticos. Com duração de 40 horas, iniciou em junho de 2015 e terminou em novembro deste mesmo ano (GEABI, 2015).

Em 2016, foi desenvolvida monitoria com os alunos do curso de Pedagogia da Universidade Federal do Pará, no projeto intitulado "Cultura, Sociedade e Relações Étnico-Raciais do Curso de Pedagogia", coordenado pela professora Doutora Vilma Aparecida de Pinho. O objetivo geral era desenvolver conhecimentos com fundamentos teórico-metodológicos da cultura e da diversidade com os discentes do curso de Pedagogia do Campus de Altamira, nas disciplinas: Educação, História e Cultura Brasileira e Africana; Fundamentos Teóricos e Metodológicos da Educação Infantil; e Educação: inclusão e exclusão social, como demonstrado no quadro 1:

Quadro 1- descrição das disciplinas e objetivos contemplados no projeto

\begin{tabular}{|l|l|}
\hline DISCIPLINA & \multicolumn{1}{|c|}{ OBJETIVO } \\
\hline Educação, História e Cultura & $\begin{array}{l}\text { Formar profissionais da Educação aptos a atuar em } \\
\text { Brasileira e Africana }\end{array}$ \\
& $\begin{array}{l}\text { contextos sociais e educacionais com reconhecimento } \\
\text { preparado para estranhar e debater situações de }\end{array}$ \\
\hline
\end{tabular}




\begin{tabular}{|l|l|}
\hline & preconceito e discriminação racial. \\
\hline FTM da Educação Infantil & Possibilitar a apropriação dos fundamentos teóricos \\
& metodológicos da educação infantil, a partir da \\
compreensão da construção histórica do conceito de & infância e das instituições e políticas de atendimento a \\
criança; das teorias do desenvolvimento e das práticas \\
e propostas pedagógicas das instituições de \\
educação infantil, bem como das formas de \\
organização e desenvolvimento do trabalho \\
pedagógico com crianças em creches e pré-escolas;
\end{tabular}

Fonte: elaborado pelas autoras a partir do PPC de Pedagogia do ano de 2011 (2018).

O total de turmas envolvidas neste projeto foram três, sendo elas: Licenciatura em Pedagogia noturna e matutina, totalizando 60 alunos e Licenciatura Pedagogia noturna, ano 2015, com 35 alunos.

A partir de 2016 começou a ser ofertada a formação em nível de pósgraduação stritu senso, curso de Mestrado acadêmico em Educação e Cultura, fazendo a formação de professores com ênfase em pesquisa a respeito da educação da população negra.

No processo de ensino/aprendizagem se valorizou a discussão sobre a estrutura racial brasileira, o racialismo e o racismo, a dinâmica cultural, social e política das relações raciais no Brasil, assim como as culturas afro-brasileiras diaspóricas com identidades e raizes culturais de resistência negra em comunidades negras e quilombolas do Baixo Tocantins, a partir da disciplina "Relações énico-raciais e educação no Brasil", cuja ementa versa sobre "A construção sócio-histórica do racismo. Raça e racialismo. Aspectos específicos da construção do racismo no Brasil. $\bigcirc$ ideal de branqueamento. A projeção do racismo nos setores sociais brasileiros. O ser negro, a educação e a diversidade étnico-racial" (GEABI, 2010, p. 5).

As ações do GEABI a partir dos componentes curriculares, seja na graduação ou na pós-graduacao e os eventos abertos se constituíram importantes espaços de formação para estudantes e professores da região Transxingu e do Baixo Tocantins. Foram muitas atividades educativas que permitiu o debate, pesquisas e reflexões acerca da situação étnico-raciais. 
Dentre essas atividades, destacamos os Seminários, os quais tiveram sua quarta edição realizada em 2018, com o tema "Afirmação de negros (as) e indígenas na educação". Nessa edição do seminário, o foco do debate recaiu sobre o problema do racismo institucional na educação e em outros setores da sociedade, a (in) exclusão de alunos (as) negros (as) e indígenas do ensino superior e a educação escolar de qualidade como um direito.

Nesse evento, reuniram-se professores/pesquisadores do campus que, de alguma maneira, tem suas pesquisas em algum âmbito dessa problemática. Ainda compuseram o debate pessoas da comunidade e ativistas dos movimentos sociais (GEABI, FOLDER IV SEMINÁRIO, 2018).

Os dados apresentados no tocante às ações desenvolvidas pelo GEABI, indicam que, este grupo tem atuado e contribuído ativamente para o fortalecimento da política de ação afirmativa, especificamente da Lei n. ${ }^{\circ}$ 10.639/2003. Isso se coloca, por meio da oferta de curso de formação para a formação docente e realizações de eventos, possibilitanto discussões sobre preconceito, racismo, discriminação e desigualdes raciais da sociedade, em especial, na Amazônia paraense. Contudo, para Gomes, Gonçalves e Silva (2011) e Oliveira (2010), muito se tem discutido sobre formação inicial e continuada de professores no Brasil, mas no que tange à diversidade étnicoracial, pouco se tem feito nos municípios.

$\mathrm{Na}$ Transxingu (Altamira) e Baixo Tocantins (Cametá) - PA, por exemplo, encontramos, segundo Freitas (2014), a deficiência da formação por parte das Secretarias Estaduais e Municipais de Educação, com uma participação quase inexistente para abordar a temática em questão. Mas, registra-se a colaboração do o IFPA - Instituto Federal do Pará ${ }^{4}$ e o GEABI UFPA que vêm, paulatinamente, propondo ações neste sentido.

Segundo Ferreira e Coelho (2019, p. 236), as problematização sobre as relações étnico-raciais nos Institutos Federais de Educação tem possibilitado - desenvolvimento de ações pautáveis nas escolas brasileiras sobre a implementação da política de ação firmativa, bem como forneceu subsídios

\footnotetext{
${ }_{4}$ As formações realizadas por esse Instituto de ensino não serão tratadas neste trabalho, para aprofundamento consultar Freitas (2014).
} 
para que a discussão fosse "incorporada nas políticas institucionais a fim de preencher a lacuna no tocante a elaboração de propostas de atuação para o acompanhamento social e pedagógico dos estudantes.

Todavia, há a necessidade de inclusão de conteúdos que abordem a temática das Relações eénico-raciais no currículo escolar, segundo Freitas (2014), tal como prever o Plano Nacional das Diretrizes Curriculares Nacionais para a Educação das Relações Étnico-raciais e para o Ensino de História e Cultura Afrobrasileira e Africana "incluir nas ações de revisão dos currículos, discussão da questão racial e da história e cultura africana, afro-brasileira e indígena como parte integrante da matriz curricular (BRASIL, 2009, p. 53)".

A relevância desta discussão acentua-se no entendimento de que os processos formativos de professores não podem acontecem distante das ações da escola, com vistas a inserção curricular da temática"Educação para as Relações Étnico-raciais (ERER); bem como a produção de material didático que contemple a valorização da história e da cultura afro-brasileira e africana (FERREIRA E COELHO, 2019).

\section{As abordagens teóricas e metodológicas do campo das ERER - Educação para as Relações Étnico-Raciais do GEABI}

Alguns conceitos do campo das relações étnico-raciais são importantes para compreender como se configuram a sociedade e as relações que se estabelecem no cotidiano, e podem tanto gerar situações de enaltecimento da cultura afro-brasileira como de preconceito e discriminação raciais. O racismo advindo das teorias racialistas que se pautam na hierarquia da diversidade humana, dividida por raças, é um importante conceito que permite compreender a origem das concepções raciais que afligem a população negra, uma vez que o racismo na sociedade brasileira se manifesta como ideologia da inferioridade. Segundo Pinho (2010), o racismo surgiu como categoria conceitual nos séculos XVII e XVIII, período em que ocorreram mudanças na compreensão da diversidade humana, passando, então, a ciência europeia a identificar e agrupar os 
sujeitos de acordo com seus traços físicos: cor da pele e dos cabelos.

No século XIX, essa classificação foi alargada pela antropologia, que utilizou, além da cor da pele e da textura dos cabelos, outros aspectos, como: o índice cefálico, o formato dos lábios, do nariz, a estatura, a condição social e cultural (PINHO, 2010). Tais características agregadas à espoliação do capital trouxeram aos negros consequências variadas, dentre elas citamos: a discriminação e o preconceito racial e social; a concepção de que as características físicas determinam as culturais; a ideia da ação do grupo sobre o indivíduocomo "um princípio determinista que alega que o coletivo influencia o indivíduo, não podendo este agir por conta própria, nem se destacar de seu grupo" (p. 36); a hierarquia universal dos valores, que acredita na superioridade das raças; políticas baseadas no saber que se fundamenta na superioridade do saber científico. Todos esses fatores reforçam a noção da submissão das raças e até mesmo a eliminação de raças inferiores, pela justificativa dos saberes científicos acumulados. Todos estes postulados afirmavam a superioridade da raça branca como um tipo ideal de ser humano (PINHO, 2010).

Por essa ótica, as teorias racistas europeias defendiam que a raça branca deveria governar a terra, pois os negros eram considerados inferiores, por isso eram colocados na esfera mais baixa da hierarquia de valores etnocêntricos que, segundo Pinho (2010), são a base de estudo da diversidade humana. Exemplo deste pensamento é a "doutrina de Comte que prevê uma única humanidade, uma única raça, a européia, que seria o modelo para as demais" (PINHO, 2010, p. 41).

No Brasil, a discussão sobre raça surge entre os anos de 1865 e 1870, com os abolicionistas, e logo foi consolidado no imaginário da sociedade brasileira o racismo. Os autores europeus foram a referência teórica dos abolicionistas, que liam suas obras sem nenhuma crítica. Desse modo, o debate sobre raça ganha, em nível nacional, conceitos científicos e passa a ser símbolo que marca a diferença e a hierarquia racial entre os povos.

Nesse período, três correntes de pensamento se colocavam como base nesta discussão, se complementavam e servindo, na prática, como 
orientações, justificativas e suporte acadêmico para pensar políticas que se pautavam na eugenia no contexto brasileiro, buscando acima de tudo uma sociedade branca. A primeira corrente de pensamento foi a poligenia, que "postulava a ideia de que as raças eram múltiplas e oriundas de várias partes do mundo criadas separadamente a partir de vários centros de nascimento" (PINHO, 2010, p. 44). Durante anos se aplicaram os estudos desta corrente de pensamento, na busca de explicar as doenças, principalmente pelas diferenças cranianas da população negra, bem como o nível de inteligência desta, chegando à conclusão de que havia diferenças inatas entre negros e brancos e degenerescência mulata.

A segunda corrente foi a histórica, que teve forte influência entre a elite brasileira. Os seguidores desta corrente "partiam do pressuposto de que a evidência histórica determinava o triunfo da raça" (PINHO, 2010, p. 44). Com Gobineau, pensador do século XX, a corrente histórica se propagou pela ideia de que a raça branca é mais enérgica e tem mais vitalidade, por isso é ela mais civilizada. Estas teorias ficaram conhecidas como as das civilizações e da história social. O Conde de Gobineau utilizou as marcas físicas das diferenças humanas para dividir a humanidade em três raças: negra, amarela e branca. Para este pensador, que viveu no Brasil, "a raça branca possuía originalmente o monopólio da beleza, da inteligência e da força" (TODOVOV apud PINHO, 2010, p. 45).

A terceira corrente do pensamento racista no Brasil foi a do darwinismo social, que postulava a ideia da sobrevivência dos mais aptos e mais fortes, ou seja, a seleção natural das espécies. Para Pinho (2010), os darwinistas descreviam os negros como pessoas rudimentares e desprovidas de inteligência e força, critérios bem próximos daqueles usados pelos pensadores poligenistas.

No período contemporâneo, o racismo - ideologia da inferioridade do negro - é bastante discutido por pesquisadores das relações étnico-raciais no Brasil. Pinho (2011), ao estudar a construção social do jovem negro em conflito com a lei, destaca que o racismo no plano subjetivo atinge esses jovens sobremaneira e, como ideologia, é vivido por sentimentos de 
inferioridade, preconceitos e discriminação racial na escola. Para eles ocorre uma desvantagem no processo de interação, que os coloca na condição de excluídos de possibilidades, sonhos e inclusão. À escola se coloca grande peso no processo de exclusão dos que lutam para adentrar e permanecer na instituição, porém, com as constantes reprovações e perseguições, eles terminam desistindo, reprovando e perdendo o sentido de permanecer nela. Alguns, por mais que estudem, não conseguem aprender, tanto que 0 processo de ensino/aprendizagem não lhes faz sentido na vida.

O racismo, o preconceito e a discriminação racial, assim como o processo de branqueamento e a democracia racial são importantes conceitos que ajudam a compreender as relações raciais no Brasil. O preconceito advém de ideias e estereótipos raciais que associam a corporeidade negra com inferioridade e com processos que ativam as imagens fixas, petrificadas com sentidos que desumanizam o ser negro. Dessa forma uma criança, um jovem ou mulher e homem negros podem facilmente ser acusados de cometer atos ilícitos, violências e toda sorte de pré-julgamentos que ativam os mitos raciais que se fundamentam na biologia do corpo classificado e apontado como sem cultura, sem ética, sem história, sem noções etc...

\begin{abstract}
O preconceito racial faz parte integrante do sistema ideológico que, numa sociedade multirracial, defende o status quo ou os privilégios do grupo dominante, estando, portanto, associado a representações coletivas, estereótipos, argumentos e racionalizações que convergem para a mesma função. Toda a preferência por famílias de determinada descendência, posse ou outras qualidades deve ser considerada como estratificação, pois que, condiciona, naturalmente, também a desvalorização de famílias ou pessoas de origem, atividade ou função diversas, na sociedade total (NOGUEIRA, 1996, p. 206).
\end{abstract}

A categoria raça ou cor nas pesquisas que estudam a realidade da população negra é importante, pois podemos inferir os mecanismos simbólicos, físicos e materiais da sociedade e vida do negro, assim como os processos históricos de perpetuação da desigualdade racial na educação e em outras esferas da sociedade. Na educação, entre pretos e pardos (negros) as pesquisas evidenciam desvantagens no acesso à escola e no 
ritmo de sua progressão, caracterizado como mais lento e acidentado (reprovações).

Com objetivos científicos agregamos a categoria de cor parda e preta ou a identificação racial pela autodeclaração racial na categoria negra. Designamos "população negra", "afro-brasileiros" para afirmar o grupo étnico e racial para fins de análise e averiguação dessa constituição de identidades, suas histórias, suas culturas e suas lutas como resistência aos processos de violência racista que se insere na história moderna da ocidentalização de culturas e modos de produção capitalistas. O racismo e o preconceito racial no Brasil não são apenas violentos e de afronta física, mas disfarçados, sem confronto direto. Nesse sentido, Pinho (2004) considera que os pesquisadores das relações raciais no Brasil elaboraram, de acordo com constatações empíricas, várias definições para as atitudes discriminatórias, 'velado', 'sutil', 'disfarçado', 'invisível', 'preterido', 'ameno' e 'cordial'.

A compreensão de Ação Afirmativa perpassa por vários campos de conhecimento que estão para além da educação, abrangendo a filosofia do direito e seus fundamentos principais que valorizam a diversidade e a diferença como constitutiva de identidades individuais e coletivas que requerem reparações mediante políticas públicas. Nessa direção, pensamos como Carvalho (2005, p. 81), para quem a Ação afirmativa

Poderia ser definida como o ato consciente e decidido de reconhecer as injustiças históricas cometidas contra os negros e apoiá-los explicitamente na direção do crescimento pessoal e profissional através de oportunidades diferenciadas para que recuperem os séculos de exploração e tratamento desigual a que foram submetidos no Brasil.

A perspectiva universalista de democracia e orientação filosófica para as especificidades se fundamenta na "orientação filosófica 'tradíciocomunitarista', que busca ao contrário do universalismo atender "as reivindicações particularistas, principalmente as de categorias sociais, minorias étnicas historicamente discriminadas ou grupos depreciados" (D'ADESKY, 2001, p. 230). 
Também os estudos de Barbosa Gomes (2005) nos ajudam situar as ações da sociedade brasileira em vista da necessidade de políticas específicas para a população negra.

[...] Cuida-se de dar tratamento preferencial, favorável, àqueles que historicamente foram marginalizados, de sorte a colocá-los em um nível de competição similar ao daqueles que historicamente se beneficiaram da sua exclusão. Essa modalidade de discriminação, de caráter redistributivo e restaurador, destinada a corrigir uma situação de desigualdade historicamente comprovada, em geral se justifica pela sua natureza temporária e pelos objetivos sociais que se visa com ela atingir (BARBOSA GOMES, 2005, p. 49).

Nesse sentido as atividades coletivas e planejadas do grupo GEABI, na transxingu e no Baixo Tocantins se pautam na noção de Ação Afirmativa de acesso ao ensino superior e permanência de jovens negros e negras, assim como nos conteúdos de ensino que preconiza a LDBN - Lei de Diretrizes e Bases de Educação, que valorizam a história e a cultura afro-brasileira; especialmente, no seu art. 26-A que orienta as Diretrizes Curriculares para a Educação das Relações Étnico-raciais, proposta legal da educação, priorizando a população negra e buscando reconfigurar no imaginário social o papel dessa população em diáspora pelo mundo.

$\S 10$ O conteúdo programático a que se refere o caput deste artigo incluirá o estudo da História da África e dos Africanos, a luta dos negros no Brasil, a cultura negra brasileira e o negro na formação da sociedade nacional, resgatando a contribuição do povo negro nas áreas social, econômica e política pertinentes à História do Brasil. § 20 Os conteúdos referentes à História e Cultura Afro-Brasileira serão ministrados no âmbito de todo o currículo escolar, em especial nas áreas de Educação Artística e de Literatura e História Brasileiras (BRASIL, 2003).

Prezamos muito pelas estratégias e lutas pela educação das famílias negras que, não raras vezes, são julgadas como permissivas e negligentes com suas crianças. Mas podemos observar nas nossas pesquisas o quanto essa população luta pela educação escolar de qualidade para seus filhos em processo de formação e cidadania. Sabe-se que o nível educacional é importante fator do bem-estar e influencia desde a renda do indivíduo até a probabilidade de morrer de forma violenta, segundo o IPEA - Instituto de Pesquisa Econômica Aplicada (2005). A educação é, ao mesmo tempo, um 
meio de transformação profunda e global da sociedade e um fator de democracia (FERNANDES, 1989, p. 13). Tal situação pode ser percebida na voz Joana Luísa, no excerto em destaque:

Foi um incentivo muito grande por mim né? Meu marido dizia, eu quero que tu estudes, mas não tem condições de estudar e eu tinha muita força de vontade. Aí eu me inscrevi contando com o projeto, que eu ia trabalhar para ganhar duzentos reais para eu pagar, que na época eram cento e sessenta reais. Acabou que não tinha o projeto, não recebi nada, não trabalhei, aí eu tirava da boca dos meus filhos praticamente, da nossa família. Eu recebia cento e doze reais, desses centos e doze reais eu inteirava com o dinheiro de corte de farinha, o dinheiro que saía eu inteirava, pagava direitinho, o objetivo era pagar o mês, para não correr juro e multa. Aí nós nos reunimos três, era eu, minha irmã e a professora Fátima. Aí a gente ia de bicicleta, estudávamos a noite, na quarta-feira a noite. Nós tínhamos bicicleta, a gente conseguiu uma bicicleta, minha mãe ajudou a comprar uma bicicleta também, aí nós íamos de bicicleta, caminhávamos dezoito quilômetros (Nome: Joana Luísa. SOBRINHO, 2019, p. 82).

O negro e a negra, portanto, se constituem desses atravessamentos de identidade que se pautam em processos de resistências. A negritude

brasileira se reconhece nos sentidos de adversidade de ser negro, tendo em vista a sociedade racista. Nesse sentido as pesquisas empreendidas pelos alunos (professores em formação básica e continuada) abordam as questões relativas à população negra, suas trajetórias de vida e desigualdade social na educação, assim como as práticas pedagógicas na escola e a cultura e história de populações negras na região da Amazônia paraense, tal como evidenciado na fala da Maria e da Rosangela, alunas do Ensino Médio:

No ensino médio mesmo, aconteceu comigo mesmo, que eu não aceitava a minha cor, a minha história, de onde vim, qual era a minha cultura e tudo mais sobre mim, e sobre a minha cor, até que passei por uma situação não muito agradável que foi de uma colega de classe, ela cortou meu cabelo e no outro dia ela trouxe meu cabelo dentro de um saquinho daqueles de bombril e saiu mostrando para todo mundo na sala de aula, como se aquilo fosse colocá-la num topo na vista de todo mundo, para acharem bonitinho aquilo, e de tudo que passei, e ouvi, que enfrentei até agora aquilo me chocou e que lembro ainda de cada detalhe, as vezes não gosto de tocar no assunto, é uma coisa que dói muito ainda (Nome: Maria, aluna do Ensino Médio. entrevista realizada em 2018). 
Eu enfrentei o racismo de frente, quando eu estudei em Cametá eu sofri na pele né? Quando eu estudei em Cametá eu senti na pele de ser uma negra né? $\mathrm{E}$ até às vezes na escola a gente sofre, porque às vezes você tem colegas que falam, acha que a gente é negra, porque a gente está numa sala de aula, porque que a gente é professora. Porque aquela preta passou no concurso e eu não passei. A gente sente na pele, mas eu como preta, me sinto orgulhosa, eu tiro de letra! Pra mim não ofende não! Ofensa seria se fosse mentira, mas é verdade, eu sou preta, eu sou professora e eu passei no concurso, pronto (Nome: Rosangela, in MOREIRA, 2019, p. 82).

O enfrentamento ao racismo, em parte, pode ser conduzido com o conhecimento. Por conta disto o GEABI investe em pesquisas que analisam os processos de discriminação racial na educação, mas também estuda as culturas de comunidades negras que mantêm rituais específicos de memória e vida de práticas religiosas, sociais e lúdicas corporais, que reafirmam suas identidades e raiz cultural e política de resistência negra.

Como afirma Benedito Lélio Caldas Costa, em seu relatório de pesquisa (2019), enquanto o racialismo com práticas de colonialismo tenta empreender a separação do ser negro de si mesmo, gerando um sentimento de desapropriação naqueles que recebiam as alcunhas raciais, influindo, assim, na autodeterminação desses indivíduos de modo a obrigá-los a ser uma adulteração de si pelo outro branco; veiculando em livros e periódicos a imagem do negro com face sofredora, imolado, ferido, indivíduos incapazes de pensar e de produzir conhecimento; fazemos o caminho inverso: o da dessemantização da ideologia racialista, do combate à visão racista e o da revelação da verdadeira postura do ser negro em relação ao ser branco.

No mesmo tom, combatendo esses dois gestos (a expropriação material e o empobrecimento antológico) que constituíram os elementos particulares da experiência negra no Brasil e do drama que dela seria o corolário, até hoje, é preciso fazer nascer um novo vaso a ser reconhecido naquilo que o identifica com a forma mais familiar do vaso originário: a força humana, na qual a estética, a ética da vida cotidiana do negro e de seus 
valores comunitários se engendram a fim de ressaltar a gigantesca energia existencial que o representa.

Com a intenção de compreender as formas de vida afro-brasileiras, Costa (2019), em seu estudo, enfoca o Bambaê do Rosário, uma prática inventada pelo negro para realizar seus ritos culturais (batuque, canto e dança) disfarçados em adoração à Virgem do Rosário, pois se alguns cantos louvam a santa católica, os instrumentos, os ritmos tocados e o ritual de cortejo são feitos à rainha(s) e rei(s) afrodescendentes.

Os estudos da cultura Afro-brasileira se fundamentam na noção de diáspora africana pelo mundo, conforme se aprende em Paul Gilroy (2001), como movimento da contradição da história da humanidade que cria outros olhares para os deslocamentos de pessoas africanas pelo mundo moderno a partir das dinâmicas, possibilidades, políticas culturais e sociais que se desenvolvem nesse processo como frutos de relações complexas. Nesse sentido, a perspectiva de diáspora não tem a pretensão de mudar a história, mas de deslocar a compreensão para dimensões mais complexas:

\begin{abstract}
Levanto essa questão não para reinscrever ontologias da raça, ou para reificar a diferença racial num momento em que seu apagamento aparece uma possibilidade, mas para consolidar e renovar nossas críticas da própria ideia de raça e esperançosamente prever sua morte como princípio de cálculo moral e político. A luta do anti-racismo não pode terminar nesta vitória parcial. Deverá haver outros confrontos. O primeiro deles é com a representação de corpo humano como repertório fundamental da ordem da verdade racial. O segundo é, como já disse, com a ideia de cultura em si. O terceiro confronto, é com o padrão de desejos e ódios... [...] que nos obriga a identificar as distintas racionalidades, lógicas, metafísicas, patologias e possibilidades de ecologias culturais, mais complexas do que aquelas articuladas sob os nomes de soberania territorial e absolutismo étnico. Sob a ideia-chave da diáspora, nós poderemos então ver não a "raça", e sim formas geo-políticas e geo-culturais de vida que são resultantes da interação entre os sistemas comunicativos e contextos que elas ano só incorporam, mas também modificam e transcendem (GILROY, 2001, p. 25).
\end{abstract}

A compreensão de negritude nas práticas pedagógicas na Educação Escolar Quilombola tem sido importante para os estudos das relações étnicoraciais no contexto escolar. A negritude, para Munanga (1998), se configura como uma luta diária e constante para a produção de uma identidade 
negra com valores positivos, ou seja, pautada em qualidades intelectuais e culturais negras. Sendo assim, o estudo da história do negro e a valorização de suas memórias são dimensões cruciais para construção de identidade da população negra e para garantia de direitos.

Esse processo de reconstrução perpassa por uma questão de natureza política no momento em que se pensa numa posição para o negro no mundo moderno, se constituindo uma posição totalmente avessa ao histórico de inferioridade ideológica e social escravocrata do negro.

Munanga (1998), ao afirmar a negritude como identidade referencial pautada na ancestralidade negra, nos convida a pensar a negritude dentro de um contexto sociocultural e político no qual, por muito tempo, teve papéis e espaços determinados. Por isso a negritude se apresenta como uma prática de combate ao racismo que historicamente levou muitos negros a terem vergonha de se assumir negros, de se perceber como parte de um grupo que teve sua história marcada por olhares negativos e estigmatizadores.

Por outro lado, Carlos Gadea, em sua obra "Negritude e Pósafricanidade: crítica das relações raciais contemporâneas", faz uma análise dos enfrentamentos e tensões produzidos entre a negritude e o racismo social e historicamente instituído.

Gadea (2013) trabalha com o conceito de espaço da negritude, entendido como tudo aquilo que se refere ao fortalecimento da identidade negra, a começar pela tomada de consciência dos grupos negros que aumentou significativamente o número de pessoas que se identificam como negras ou pardas, muito embora a segunda categoria se revele como uma prática indiferente no que tange às questões raciais.

Para Gadea (2013) o próprio posicionamento étnico-racial dos sujeitos indica o sentimento de pertença que ainda demarca as formas de vida e todo o conjunto social que integra a identidade dos sujeitos. Por isso o autor considera que "As marcas da negritude já não são simples marcações identitárias, mas sim espaços a serem (des)colonizados" (GADEA, 2013, p. 21). 
Tais considerações nos levam a pensar o negro não como uma categoria simplória, como propuseram os marxistas ao reduzir as questões raciais a condições e conflitos de classe, mas sim como construtos cuja complexidade política e social da diferença produz as identidades na luta pela equidade de direitos.

O esforço de construção e desenvolvimento do espaço da negritude, de acordo com Gadea (2013), inicia pela admissão da tensão no reconhecimento dos grupos negros de que na narrativa oficial se encontram em posição de subalternidade, e é neste contexto que os espaços da negritude passam a reivindicar sua afirmação e reconhecimento racial e sociocultural, assim como a superação de uma sociedade racista e culturalmente dominada pelos brancos. Aos olhos do autor, assumir o espaço da negritude significa combater o discurso preconceituoso e discriminatório de inferiorização do negro, pois toda e qualquer identificação racial é marcada por uma performance atravessada por orientações político-sociais e ideológicas que se orientam a partir de espaços e movimentos.

Essas são as principais abordagens teóricas e metodológicas que utilizamos em nossas propostas de ensino, pesquisa e extensão, dadas a complexidade da sociedade brasileira e a condição da população negra no Brasil, sobretudo na especificidade da Amazônia paraense - Transxingu (Altamira) e Baixo Tocantins (Cametá) - PA.

\section{Conclusão}

Apesar dos limites e dificuldades, O GEABI na Transxingu (Altamira) e Baixo Tocantins (Cametá) - PA proporcionou discussão sobre a Lei $n^{\circ}$ 10.639/2003, fomentando o processo de formação continuada para a diversidade. Além disso atuou como elemento impulsionador de mudanças pedagógicas para a inclusão de alunos/as negros/as na escola, ao possibilitar a formação de professores para o trato das questões em Relações Étnico-raciais. 
Nesse sentido, verificamos que as contribuições do Grupo de estudos afro-brasileiros e indígenas - GEABI para formação de professores em Relações Étnico-raciais, em Altamira - PA, a partir da Lei no 10.639/2003, foi discutir e constituir o desenvolvimento de práticas pedagógicas pautadas em concepções sociopolíticas, com abordagens teóricas e metodológicas que enfocam o protagonismo da cultura Afro-brasileira, o combate ao preconceito, à discriminação racial e ao racismo - visto ser o racismo na sociedade brasileira um importante marcador de exclusões, manifestando-se por meio da ideologia da inferioridade.

Na escola, o racismo é responsável por reprovações, perseguições, humilhações, dentre outros fatores que interferem no sucesso de crianças e jovens em seus processos de aprendizagem. Assim, o racismo, o preconceito e a discriminação carregam ideais estereotipados de identidade e de cultura, além de estabelecer relações de inferioridade com a corporeidade negra, situação historicamente perpetuada nos mecanismos simbólicos, físicos e materiais da sociedade brasileira.

Ao trabalhar teórica e metodologicamente questões acerca do racismo, discriminação, preconceito, cultura afro-brasileira e desigualdade racial na escola e na sociedade, O GEABI evidenciou paulatinamente a construção histórica desses marcadores no Brasil - situação importante para delimitar as desvantagens no acesso de pretos e pardos (negros) à escola, à sua permanência e progressão.

Ainda por meio dos encontros, o GEABI abordou a questão da identidade e a cientificidade da categoria de cor parda e preta ou a identificação racial por meio da autodeclaração racial na categoria negra, tal como é trabalhada teoricamente. Neste caso pontuamos a compreensão do GEABI acerca da categoria racial - designada por "população negra" e "afro-brasileiros", como afirmação do grupo étnico, racial, identitário, histórico, cultural e político.

Essa delimitação, a nosso ver, amplia o campo dos conhecimentos epistemológicos e políticos, pois se fundamenta no entendimento das identidades coletivas e dos direitos, com destaque para as Ações Afirmativas 
- que no âmbito das políticas públicas são medidas temporárias que têm a preocupação de promover o acesso das minorias aos direitos sociais básicos (educação e ao trabalho), na sua dimensão prática, em razão de processos de discriminação histórica.

Em meio a toda a diversidade cultural dos negros, as Ações Afirmativas partem do princípio epistemológico de justiça compensatória e distributiva. Como justiça compensatória, as ações afirmativas se propõem a reparar por meio da garantia de direitos constitucionais perdas sociais, econômicos e culturais historicamente causadas aos negros. Pela justiça distributiva, as políticas de ações afirmativas visam oportunizar aos negros a aquisição de benefícios, que durante anos estiveram sob o poder de um grupo em detrimento de outros. A justiça distributiva se justifica devido à escravidão, ao racismo e à discriminação social que viveram os negros brasileiros. Parecenos legítimo que o Brasil possa, por intervenção das ações afirmativas, devolver-Ihes a dignidade e o respeito negados historicamente.

Defendemos a ideia de que a justiça compensatória e a distributiva são democráticas e têm a possibilidade de eliminar as desigualdades raciais, porque compõem políticas mais densas, como é o caso das ações afirmativas. Contudo, no contexto brasileiro, vários são os argumentos contrários a elas [ações afirmativas], dos quais destacamos dois. O primeiro é que as ações afirmativas servirão para dividir a nação entre negros e brancos, este argumento é defendido pela pesquisadora Yvonnor Maggie em 2013; o segundo argumento é que o Brasil é um país híbrido e a implementação de políticas de ações afirmativas negará tudo isto ocorrendo assim a distinção entre raças - este pensamento é propagado pelo estudioso Peter Fry (2013).

Discordâncias à parte, o que nos interessa nesse momento é pontuar que as Ações Afirmativas são, na concepção do GEABI, políticas que visam combater os resultados das práticas discriminatórias, os processos históricos de exclusão, as desigualdades raciais, o preconceito e todas as formas de racismo. Neste ínterim, as atividades geridas pelo grupo pautaram-se na noção de Ação Afirmativa de acesso, permanência e progressão n escola 
(básica superior) de crianças e jovens negros e negras, como preconizado pela Lei de Diretrizes e Bases da Educação, no artigo 26.

Em relação às repercussões dessa formação para as práticas pedagógicas dos professores, temos a relatar que:

a) de acordo com os documentos analisados, as formações estão pautadas nos referencias teóricos e metodológicos sociopolíticos da Educação para as Relações Étnicos-Raciais - ERER, de tal forma que as implicações metodológicas na sua prática pedagógica são baseados nos referenciais de positivação da raça/cor como marcador fundante da discriminação e do preconceito racial sofrido pelos negros na sociedade e na escola, ao longo da história brasileira, pois os relatórios estudados revelaram que juntas, raça e cor, "expulsam" o educando do sistema educativo, por meio da reprovação e da evasão escolar. Por sua vez, são consideradas ações que "marginalizam" crianças e jovens negros/as que, comumente, são estigmatizados pela sociedade.

b) a prática dos professores sofreu mudanças sociopolíticas, no que se refere às Relações Étnico-Raciais. Isso se deve ao envolvimento dos formandos nas ações, experiências, oficinas e atividades escolares propostas pelo GEABI. Estas ações e participações, segundo os dados analisados, na visão dos professores estão cheias de significados conflituosos na relação entre negros e brancos na sociedade e, em particular, no ambiente de sala de aula.

c) as ações formativas fomentadas pelo GEABI, de modo geral, comtemplaram o ensino da História e da Cultura Afro-Brasileira no currículo escolar, como determina a Lei n 10.639/2003. Entretanto, marcadores como racismo, discriminação, preconceito, identidade e ações afirmativas foram bem mais discutidos nos encontros.

d) os conteúdos explorados nas formações ajudaram os professores no trato das questões raciais em sala de aula, bem como na discussão da valorização e identificação racial, 
De modo geral, inferimos que as políticas de formação docente contribuíram para mudanças no cenário altamirense e, indiretamente, o atual contexto educacional brasileiro, que tem sido caracterizado por conflitos, no que se refere à formação docente. Conflitos estes divididos em dois movimentos: (a) que atribui ao espaço formativo a função de preparar futuros professores nas competências entendidas como centrais em um mundo globalizado; (b) que compreende tal espaço como campo discursivo com potenciais de atuação na construção de identidades docentes críticas, comprometidas com a valorização da pluralidade cultural. Este segundo movimento está relacionado à proposta de uma nova escola com um novo currículo defendido por Arroyo (2010), Gomes e Gonçalves e Silva (2011) e Banks (2006), que contemple o diálogo e o reconhecimento de uma nova construção sociohistórica, política e cultural de nossa sociedade.

Destarte inferimos que as repercussões destas formações foram positivas na prática pedagógica dos docentes egressos dos cursos ofertados pelo GEABI no sentido de interferir no processo de construção da identidade racial e na positivação da raça de si e de seus educandos, de forma a contribuir na autoclassificação sem restrições, ao mesmo tempo, colaborando para promoção da consciência política na busca de inserir, via currículo, os conteúdos relacionados à questão das relações étnico-raciais negras em suas escolas, apesar da complexidade dos seus fazeres docentes.

Registramos aqui que o GEABI-UFPA fez constar em seus relatórios que enfrentou dificuldades nos processos formativos dos docentes. Citamos a falta de liberação dos professores para participarem das atividades e o envolvimento da equipe técnico-pedagógica das escolas na proposta de formação. No que tange aos professores, a formação ocorreu aos sábados ou finais de tarde e noites de sexta feira, fora do horário de expediente. Isto refletiu de forma negativa na qualidade da formação, pois os professores não conseguiram se desprender dos assuntos cotidianos da escola. 


\section{REFERÊNCIAS}

ARROYO, Miguel González. A pedagogia multirracial popular e o sistema escolar. In: BANKS, James A. Reformando escolas para implementar igualdade para diferentes grupos raciais e étnicos. In: OLIVEIRA, Iolanda; SISS, Ahyas. Cadernos Penesb: População negra e educação escolar, n 7 . Rio de Janeiro: QUARTET/EdUFF, 2006.

BARBOSA GOMES J. A Recepção do Instituto da Ação Afirmativa pelo Direito Constitucional Brasileiro. In Ações Afirmativas e Combate ao Racismo nas Américas / Sales Augusto dos Santos (Organizador). - Brasília: Ministério da Educação: UNESCO, 2005. p/p 47-82.

BRASIL. Ministério da Educação. Diretrizes curriculares nacionais para a educação das relações étnico-raciais e para o ensino de história e cultura afro-brasileira e africana. Brasília: MEC, 2004.

BRASIL. Orientação e ações para a educação das relações étnico-raciais. Ministério de Educação / Secretaria de Educação Continuada.

Alfabetização e diversidade (MEC / SECAD) Brasilia, 2006.

BRASIL. Plano Nacional das Diretrizes Curriculares Nacionais para a Educação das Relações Étnico-raciais e para o Ensino de História e Cultura

Afrobrasileira e Africana. Brasília: SECAD; SEPPIR, jun. 2009. Disponível em: http://portal.mec.gov.br/index.php?option=com_docman\&view=download \&alias=1852-diretrizes-curriculares-pdf\&category_slug=novembro-2009pdf\&ltemid=30192. Acesso em: 30/06/2020.

BRASIL. Lei $\mathbf{n}^{\circ} \mathbf{1 0 . 6 3 9}$ de 09 de janeiro de 2003. Disponível em: http://www.planalto.gov.br/ccivil_03/Leis/2003/L10.639.htm. Acesso em: 14 abr. 2017.

BRASIL. Lei $\mathbf{n}^{\circ} \mathbf{9 . 3 9 4}$ de 20 de dezembro de 1996. Disponível em: http://www.planalto.gov.br/ccivil_03/leis/19394.htm. Acesso em: 14 abr. 2017.

CARVALHO. José Jorge. Inclusão étnica e racial no Brasil: a questão das cotas no ensino superior. São Paulo: Attar editora, 2005.

COSTA. Benedito Lélio Caldas. Relatório de pesquisa. PPGEDUC/Cametá, 2019.

D'ADESKY, J. Pluralismo étnico e multiculturalismo: racismos e anti-racismos no Brasil. Rio de Janeiro: Pallas, 2001.

FERREIRA. Anne de Matos Souza. COELHO, Wilma de Nazaré Baía. Ações dos núcleos de estudos afro-brasileiros (neabs) institucionalizados dos institutos federais de educação, ciência e tecnologia (ifets) no período de 2006 a 
2017. In. Revista Exitus. Santarém, Vol. 9, № 5, p. 215 - 242, Edição Especial 2019.

FERNANDES. Florestan. O desafio educacional. São Paulo: Autores Associados. 1989.

FREITAS, Léia Gonçalves de. Estudo das práticas pedagógicas de professores egressos do programa de formação em educação para relações étnicoraciais - ERER no município de Altamira - Pará. [manuscrito] Anápolis, Goiás, 2014.

FRY, Peter. O que a cinderela negra tem a dizer sobre a "política racial" no Brasil. In. Revista USP. São Paulo: USP, n² 28, dez/fev. 1995/1996. Disponível em:http://pt.scribd.com/doc/142307638/FRY-P-O-que-a-cinderela-negratem-a-dizer-sobre-apolitica-racial-no-Brasil>.Acesso em novembro, 2013.

GADEA, Carlos A. Negritude e Pós-Africanidade: Crítica das relações raciais contemporâneas. Porto Alegre; Sulina, 2013. 134p

GILROY. Paul. O Atlântico Negro: modernidade e dupla consciência. São Paulo: ed. 34. Rio de Janeiro: editora Cândido Mendes, 2001.

GOMES, Nilma Lino; GONÇALVES E SILVA, Petronilha Beatriz. (Org.)

Experiências étnico-culturais para a formação de professores. $2^{a}$ ed. Belo Horizonte: Autêntica, 2011.

LUDKE, Menga. ANDRÉ, Marli E. D. A. Pesquisa em educação: abordagens qualitativas. São Paulo: EPU, 2012.

MAGGIE. Ivonne. Mário de Andrade ainda vive? O ideário modernista em questão. In. Revista Brasileira de Ciências Sociais. São Paulo, v. 20, n 58, jun. 2005b. Disponível em: http://www.scielo.br/pdf/rbcsoc/v20n58/25626.pdf. Acesso em: 30 de novembro de 2013.

MAZZILLI, Sueli. Ensino, pesquisa e extensão: reconfiguração da universidade brasileira em tempos de redemocratização do Estado. Revista RBPAE - v.27, n.2, p. 205-221, maio/ago. 2011.

MUNANGA, Kabengele. Negritude: Usos e sentidos. - 2. ed. - São Paulo: Editora Ática, 1988

NOGUEIRA, Oracy. Preconceito de Marca: as relações raciais em Itapetininga. São Paulo: editora da Universidade de São Paulo, 1998.

OLIVEIRA. Iolanda de. Raça, currículo e práxis pedagógicas: relações raciais e educação - o diálogo teoria/prática na formação de profissionais do magistério. In. Cadernos PENESB. Especial ERER - Periódico do programa de 
educação do negro na sociedade brasileira n. 12. FEUFF, Niterói:

ALTERNATIVA/EdUFF, 2010.

PINHO, Vilma, Aparecida de. Relações raciais no cotidiano escolar:

percepções de professores de Educação Física sobre alunos negros. 2004.

154 f. Dissertação Mestrado/PPGE-UFMT Universidade Federal de Mato

Grosso, Cuiabá, 2004.

PINHO, Vilma, Aparecida de. Jovens negros em processo de

"ressocialização": trajetórias de vida e escolarização. Tese de Doutorado.

Programa de pós-graduação da Universidade Federal Fluminense, Niterói -

RJ: PENESB, 2010.

PINHO, Vilma, Aparecida de. Jovens negros em conflito com a lei: escola e trajetórias. Revista Educação em Questão, Natal, v. 41, n. 27, p. 107-138, jul./dez. 2011. Disponível em:

https://periodicos.ufrn.br/educacaoemquestao/article/download/4004/3271

L. Acessado em 22 de fevereiro de 2019.

SOBRINHO. Alice, Moreira. Narrativas Mupinses: um estudo sobre as estratégias de acesso a educação na Vila do Torrão-Mupi. Dissertação de Mestrado/PPGEDUC-UFPA. 2019.

Fontes documentais

GEABI. Interdisciplinaridade, ensino, pesquisa e extensão em práticas pedagógicas inovadoras no laboratório de pedagogia. Altamira: UFPA, 2010.

GEABI. História e cultura afro-brasileira e indígena: políticas educacionais, currículo e identidade. Faculdade de Educação. Altamira: UFPA, 2012.

GEABI. Projeto Pedagógico do curso de especialização em Educação, diversidade e sociedade. Faculdade de educação. Altamira: UFPA, 2013.

GEABI. Fatores de proteção e risco no contexto da grande obra de UHE de Belo Monte: analisa os impactos socioambientais e culturais na formação de criança e adolescente de famílias remanejadas. Relatório. Altamira, 2014.

GEABI. História e Cultura Afro-brasileira. Relatório. Altamira, 2015.

GEABI, FOLDER IV SEMINÁRIO. Afirmação de negros e indígenas na Educação. Altamira, UFPA, 2018.

PROJETO PEDAGÓGICO DO CURSO DE PEDAGOGIA. Faculdade de Educação - UFPA. Altamira, 2011. 
Recebido em: 05 de abril de 2019 Aprovado em: 16 de junho de 2020 Publicado em: 01 de setembro de 2020

(c) $(1) \circledast$ 